\title{
Prerace medical screening and education reduce medical encounters in distance road races: SAFER VIII study in 153208 race starters
}

Martin Schwellnus, Sonja Swanevelder, Wayne Derman, Mats Borjesson, Karen Schwabe and Esme Jordaan

\begin{abstract}
Objectives To examine the efficacy and feasibility of an online prerace medical screening and educational intervention programme for reducing medical complications in long-distance races.

Methods This was an 8-year observational study of medical encounter rates among 153208 Two Oceans race starters $(21.1$ and $56 \mathrm{~km}$ ) in South Africa. After the first 4-year control (CON) period, we introduced an online prerace medical screening (based on European pre-exercise screening guidelines) and an automated educational intervention programme. We compared the incidence of medical encounters (per 1000 starters; all and serious life threatening) in the CON versus the 4-year intervention (INT) period.

Results In comparison to the CON period (2008-2011: 65865 starters), the INT period (20122015: 87343 starters) had a significantly lower incidence (adjusted for age group, sex, race distance) of all medical encounters by $29 \%(\mathrm{CON}=8.6(7.9-9.4)$; INT=6.1 (5.6-6.7), $\mathrm{p}<0.0001)$, in the $21.1 \mathrm{~km}$ race by $19 \%(\mathrm{CON}=5.1(4.4-5.9) ; \mathrm{INT}=4.1(3.6-4.8), \mathrm{p}=0.0356)$ and in the $56 \mathrm{~km}$ race by $39 \%$ $(\mathrm{CON}=14.6$ (13.1-16.3); INT=9.0 (7.9-10.1), $\mathrm{p}<0.0001)$. Serious life-threatening encounters were significantly reduced by $64 \%(\mathrm{CON}=0.6(0.5-0.9) ; \mathrm{INT}=0.2(0.1-0.4) ; \mathrm{p}=0.0003)$ (adjusted for age group and sex). Registration numbers increased in the INT period ( $\mathrm{CON}=81345 ; \mathrm{INT}=106743)$ and overall \% race starters were similar in the CON versus INT period. Wet-bulb globe temperature was similar in the CON and INT periods.

Conclusion All medical encounters and serious life-threatening encounters were significantly lower after the introduction of a prescreening and educational intervention programme, and the programme was feasible.
\end{abstract}




\section{What are the findings?}

- An online prerace medical screening and educational intervention programme may significantly reduce medical encounters and alter race starter risk profile.

- It is feasible to implement an online prerace medical screening and educational intervention programme at a mass community-based running event.

- The results of this study have the potential to change current practice of providing medical care at mass community-based endurance sports events worldwide.

- Race organisers and race medical teams may consider implementing such programmes to improve race safety.

\section{How might it impact on clinical practice in the}

\section{future?}

- Race medical directors and race organisers may consider implementing an online prerace medical screening and educational intervention programme at mass community-based endurance events.

- Race medical directors and race organisers can document the impact of implementing such programmes.

- Implementation of prerace medical screening and education could lead to improved race safety.

- The results of this study have the potential to change policy. 


\section{Introduction}

Regular physical activity (PA) is an important lifestyle intervention for primary and secondary prevention of non-communicable disease. ${ }^{1-5}$ The recommended minimum weekly healthy 'dose' of exercise is 150 min at moderate to vigorous intensity. $5^{-7}$ Mass communitybased sports events such as distance running events have, over the last two to three decades, seen substantial growth in participant numbers, ${ }^{8}$ with a notable increase in older participants (http://www.runningusa.org/annual-reports). While regular PA has numerous health benefits, PA is associated with medical encounters, 910 including acute myocardial infarction and sudden death. ${ }^{11-16}$

The reported absolute risk of sudden death during marathons, and similar races, varies between 0.004 and 0.033 per 1000 race entrants. ${ }^{17-23}$ The incidence of other non-cardiac, but serious life-threatening medical encounters during running is not well studied, ${ }^{22-28}$ but is about 0.5 per 1000 race entrants (0.17-1.55 per 1000 race entrants). ${ }^{22} 2328$ To reduce the risk of acute medical complications during sport, precompetition medical evaluation has been proposed, with the main focus on younger elite athletes. ${ }^{14}$ 29-33 However, the older exercising population has a higher incidence of acute medical complications during exercise34 and a number of international organisations developed consensus recommendations for preparticipation screening of master athletes $35-37$ or middle-aged/senior individuals wishing to engage in leisure time sports (European Association for Cardiovascular Prevention and Rehabilitation, EACPR). ${ }^{29}$ We recently reported that using the EACPR guidelines, $>30 \%$ runners would require a full medical assessment before race participation-mainly linked to runners reporting musculoskeletal conditions. We therefore suggested a revision of these guidelines and proposed that prerace screening be considered to identify runners with a 'very high', 'high' and 'intermediate risk' for medical complications during exercise. 38 We are not aware of any studies investigating the efficacy of preparticipation medical screening to reduce acute medical encounters in athletes who engage in leisure time sports such as mass community-based distance running events.

Therefore, the primary aim of this study was to determine the efficacy of an online preparticipation screening and educational intervention programme to reduce the incidence of acute medical encounters, including serious life-threatening encounters and deaths, at distance running events. Secondary aims were to: (A) explore whether the screening and intervention strategy could be easily or conveniently performed (feasibility); (B) examine if extrinsic factors such as environmental stress could account for variation in medical encounters rather than the prescreening; and (C) determine if the intervention programme altered the race entrant risk profile.

\section{Methods study design}

We conducted an observational study over 8 years with a 4-year initial control (CON) period (2008-2011) and a subsequent 4-year intervention (INT) period (2012-2015). 


\section{Participants and data collection}

The Two Oceans Marathon races are mass community-based running events in South Africa and comprise a $21.1 \mathrm{~km}$ and a $56 \mathrm{~km}$ race. Entries to the $21.1 \mathrm{~km}$ race are open to novice runners and require no qualifying time, while entry for the $56 \mathrm{~km}$ race requires a sub-5-hour 42.2 $\mathrm{km}$-qualifying time. Entrants, defined as any runner registering for the races (typically open $3-5$ months before the races), for both races over an 8-year period (2008-2015) were considered as participants. In each of the 8 years of the study (control and intervention) race entrant data (demographics including age, sex, previous participation and previously completed races) and race day data (number of starters and finishers) were obtained, with permission, from the race organisers. Demographic and race data are in the public domain and are obtainable from the race website.

In each year of the study (CON and INT periods), we obtained the deidentified data on medical encounters in runners who presented to the medical facilities on race day, with permission, from the race medical team and the race organisers. Medical facilities consisted of on-route medical stations and a medical facility at the finish. For the purposes of this study, a medical encounter was defined as 'any runner who required medical care on race day that was severe enough to warrant a medical assessment by a doctor, either in the medical facility at the end of the race, on route at the medical stations, or at one of the referral hospitals (for runners that were assessed by medical staff on the route)'. Minor medical encounters (not requiring an assessment by a medical doctor) were not included in our study. A serious life-threatening medical encounter was defined as 'a medical encounter that could result in death unless urgently diagnosed and treated, specifically encounters that resulted in either admission to a high-care (intensive care and observation) medical area at the event, or transport (with or without admission) to a hospital'. An event-related sudden death was defined as 'a medical encounter that resulted in sudden death, where the medical problem resulting in death was deemed to be directly related to the event, and the onset of the medical problem occurred during the event or within 24 hours of the finish time'. Race physicians recorded accurate and detailed clinical information of each medical encounter in a standardised format.

\section{InT period: online prerace medical screening, risk stratification and educational intervention}

In the INT period (2012-2015), we introduced a compulsory online prerace medical screening questionnaire or 'self-assessment of risk' based on the EACPR guidelines. ${ }^{29} 39$ The questionnaire consisted of the following main categories of medical history: cardiovascular disease (CVD), symptoms of CVD, risk factors for CVD, other chronic disease (respiratory disease, metabolic or hormonal disease, gastrointestinal disease, nervous system disease, renal or bladder disease, haematological or immune system disease, cancer, allergies), general prescription medication use, medication use during racing and a history of collapse during racing (online supplementary table $\mathrm{S} 1$ ). Algorithms were developed to risk stratify runners into one of four risk categories (online supplementary table S2), based on the EACPR guidelines. ${ }^{29}$ 39 Risk stratification was performed on completion of the online screening process in an 
automated fashion and runners completing the screening were given the opportunity to consent that their data could be used for research purposes.

\section{Educational intervention programme}

In conjunction with the online prerace medical screening questionnaire, an educational intervention programme was developed to educate runners, via automated email, on the potential medical complications that may occur during moderate to high-intensity exercise (online supplementary table S3). Educational material was delivered to runners in the two highest risk categories ('very high risk' and 'high risk') by personalised email and they were specifically advised to seek clearance from their medical practitioner. In addition, we conducted a general educational intervention to all runners through weekly posts on a dedicated medical section of the official race website, and regular email notification to all runners to visit the race website. No runner was prevented from race participation by the race organisers or the race medical team. Thefinal decision torun on race day was left to the runner and his/her medical practitioner.

\section{Primary outcome measures to assess efficacy Incidence of race day medical encounters}

The incidence of all medical encounters, serious life-threatening medical encounters and deaths was the main outcome measure to assess efficacy of the intervention. The incidence was calculated as the number of runners with medical encounters or deaths per 1000 race starters. The main analysis was by observation period (control: 2008-2011; intervention: 2012-2015), with further analysis of the incidence in subgroups by race distance $(21.1 \mathrm{~km}$ or $56 \mathrm{~km}$ race).

\section{Secondary outcome measures}

Race entrant numbers, did-not-start rate and did-not-finish rate For the purposes of this study, we used additional main outcomes to address possible concerns of race organisers that the screening and intervention programme may reduce race entry numbers, or increase dropout after race entry by reducing the number of race starters:

- The number of race entrants was defined as the number of runners registered for the races (typically 3-5 months before the races). The rationale for this outcome measure is that race organisers may express a possible concern that by implementing the intervention, it may negatively affect race entries.

- Race starters were defined as race entrants who started the race and we report the did-not-start (DNS) rate (\% entrants who did not start the race). The runners who started, but did not finish the race, is reported as did-not-finish (DNF) rate (\%). The rationale for these outcome measures is to address a potential concern that the intervention may result in a greater \% race entrants not starting or finishing the race.

\section{Influence of environmental stress on medical encounter rates}

We collected data on environmental conditions (hourly from 06:00 to 12:00) on race day of each year (temperature, humidity, rainfall, cloud cover and wind speed) from the database of the South African Weather Services (with permission). We used the wet-bulb globe temperature (WBGT) Index (calculated using WBGT $\left({ }^{\circ} \mathrm{C}\right.$ ), humidity, time of day and cloud cover data) as the main outcome variable to assess if environmental stress affected medical encounter rates. 


\section{Risk profile of race starters changed in the intervention}

In the INT period, 87343 runners started the race, and 76654 runners (87.8\% of starters) gave consent that their medical information (risk category data) could be used for research purposes. Data on the \% race starters in each risk category (online supplementary table S3) were only available in the INT period. The DNS in the INT period was used as an outcome variable to determine if the risk profile of race starters changed in the 4-year INT period.

\section{Statistical analysis of data}

All analyses were done using the SAS (V.9.4) statistical analysis system. Modified Poisson regression models using a robust error estimator (log link function) to estimate the incidence rates (IR) and CIs were used to analyse all medical outcomes. The correlated structure of the data, due to the same athletes taking part in several of the races over the 8-year study period, was accounted for by using an unstructured correlation matrix. Data are provided to show the number of unique athletes in the CON and INT periods. The estimate of the prevalence risk and 95\% CI for the CON and INT periods were reported and the estimated relative risk (RR) was reported as a measure of the intervention effect. Models compared outcomes CON and INT, reporting prevalence risks and 95\% CIs.

Models for any medical encounters included the individual years, and contrasted CON (20082011) versus INT (2012- 2015) years to obtain RRs and 95\% CIs. Models for serious lifethreatening/death medical encounters included an indicator for CON and INT to obtain RRs and 95\% CIs.

Unadjusted model results for medical encounters are reported in the online supplementary appendix. Adjusted models included possible confounders of race distance, sex and age category to adjust the intervention estimates. The interaction term for race distance and year was included to obtain separate estimates for the two race distances.

The possible influence of environmental stress on the association between medical encounters and the intervention was assessed by including wind speed and WBGT index as a confounder in the final model.

For the comparison of risk categories for chronic illness, the 'very high risk' and 'high risk' categories were combined and the 'intermediate risk' and 'low risk' categories were combined in a model that was adjusted for age category, sex and race distance.

\section{Results}

\section{Study population and overall race starter demographics}

Over the 8-year study period, a total of 87525 unique runners were studied: 26753 runners who only took part in the CON period, 38719 who only took part in the INT period and 22 o53 runners who took part in both periods. In the 8-year study period, there were 188 o88 race entrants and 153208 race starters (81.5\%). Demographic details of all race starters in the CON and INT periods are available in the online supplementary table S4. The study population for the 
$\mathrm{CON}$ and INT periods included 92038 male starters $(\mathrm{CON}=41$ 026; INT $=51$ 012) and 61170 female starters $(\mathrm{CON}=24$ 839; INT=36 331).

\section{Incidence of medical encounters (COn vs InT period)}

\section{All medical encounters}

The unadjusted (crude) incidence of all medical encounters is available in the online supplementary table $\mathrm{S}_{5}$. The adjusted (age category, sex) incidence (per 1000 race starters) of all medical encounters in all runners ( $\mathrm{p}<0.0001), 21.1 \mathrm{~km}$ runners $(\mathrm{p}=0.0356)$ and $56 \mathrm{~km}$ runners $(\mathrm{p}<0.0001)$ was significantly lower in the INT period-a $29 \%$ reduction in all runners, and a $19 \%$ and $39 \%$ reduction in the 21.1 and $56 \mathrm{~km}$ runners, respectively (table 1 ).

The number needed to treat (NNT) statistic of the screening and educational intervention to prevent one medical encounter is 394 for all runners, 1053 for $21.1 \mathrm{~km}$ runners and 177 for $56 \mathrm{~km}$ runners.

\begin{tabular}{|c|c|c|c|c|c|c|c|c|c|c|c|}
\hline & \multicolumn{5}{|l|}{ CON period } & \multicolumn{5}{|l|}{ INT period } & \multirow{2}{*}{$\begin{array}{l}\text { RR } \\
\text { (CON vs INT) }\end{array}$} \\
\hline & 2008 & 2009 & 2010 & 2011 & All CON & 2012 & 2013 & 2014 & 2015 & All INT & \\
\hline $21.1 \mathrm{~km}$ & $\begin{array}{l}4.87 \\
(3.66 ; 6.47)\end{array}$ & $\begin{array}{l}3.98 \\
(2.95 ; 5.38)\end{array}$ & $\begin{array}{l}4.98 \\
(3.75 ; 6.61)\end{array}$ & $\begin{array}{l}6.98 \\
(5.50 ; 8.87)\end{array}$ & $\begin{array}{l}5.09 \\
(4.42 ; 5.87)\end{array}$ & $\begin{array}{l}2.21 \\
(1.54 ; 3.17)\end{array}$ & $\begin{array}{l}4.89 \\
(3.86 ; 6.20)\end{array}$ & $\begin{array}{l}6.16 \\
(4.95 ; 7.67)\end{array}$ & $\begin{array}{l}4.42 \\
(3.44 ; 5.69)\end{array}$ & $\begin{array}{l}4.14 \\
(3.60 ; 4.76)\end{array}$ & $\begin{array}{l}0.81 \\
(0.67 ; 0.99)^{*}\end{array}$ \\
\hline $56 \mathrm{~km}$ & $\begin{array}{l}12.51 \\
(9.87 ; 15.85)\end{array}$ & $\begin{array}{l}18.60 \\
(15.31 ; 22.61)\end{array}$ & $\begin{array}{l}11.95 \\
(9.66 ; 14.79)\end{array}$ & $\begin{array}{l}16.41 \\
(13.42 ; 20.06)\end{array}$ & $\begin{array}{l}14.62 \\
(13.08 ; 16.34)\end{array}$ & $\begin{array}{l}10.47 \\
(8.38 ; 13.07)\end{array}$ & $\begin{array}{l}7.91 \\
(6.16 ; 10.16)\end{array}$ & $\begin{array}{l}11.75 \\
(9.56 ; 14.46)\end{array}$ & $\begin{array}{l}6.63 \\
(5.12 ; 8.60)\end{array}$ & $\begin{array}{l}8.96 \\
(7.93 ; 10.13)\end{array}$ & $\begin{array}{l}0.61 \\
(0.52 ; 0.72) \dagger\end{array}$ \\
\hline All & $\begin{array}{l}7.80 \\
(6.48 ; 9.40)\end{array}$ & $\begin{array}{l}8.61 \\
(7.20 ; 10.30)\end{array}$ & $\begin{array}{l}7.71 \\
(6.47 ; 9.20)\end{array}$ & $\begin{array}{l}10.70 \\
(9.16 ; 12.51)\end{array}$ & $\begin{array}{l}8.63 \\
(7.89 ; 9.44)\end{array}$ & $\begin{array}{l}4.81 \\
(3.89 ; 5.94)\end{array}$ & $\begin{array}{l}6.22 \\
(5.24 ; 7.39)\end{array}$ & $\begin{array}{l}8.51 \\
(7.33 ; 9.89)\end{array}$ & $\begin{array}{l}5.42 \\
(4.52 ; 6.49)\end{array}$ & $\begin{array}{l}6.09 \\
(5.56 ; 6.68)\end{array}$ & $\begin{array}{l}0.71 \\
(0.62 ; 0.80) \ddagger\end{array}$ \\
\hline
\end{tabular}

Table 2 The adjusted (by age category and sex) incidence (per 1000 runners starting the race: $95 \% \mathrm{Cl}$ ) and relative risk of serious (life-threatening/death) medical encounters in the control versus intervention period, and by race type

\begin{tabular}{llll}
\hline & CON period & INT period & RR (CON vs INT) \\
\hline $21.1 \mathrm{~km}$ & $0.5(0.4-0.8)$ & $0.2(0.1-0.3)$ & $0.26(0.12-0.60)^{*}$ \\
$56 \mathrm{~km}$ & $0.7(0.5-1.1)$ & $0.3(0.1-0.5)$ & $0.48(0.22-1.05) \dagger$ \\
All & $0.6(0.5-0.9)$ & $0.2(0.1-0.4)$ & $0.36(0.21-0.62) \ddagger$ \\
\hline
\end{tabular}

* $P=0.0014$.

$\mathrm{tP}=0.0666$.

$\neq \mathrm{P}=0.0003$.

CON, control; INT, intervention; RR, relative risk.

\section{Serious life-threatening (including death) medical encounters}

There were only 39 and 19 serious life-threatening (including death) medical encounters, respectively, in the CON and INT periods, therefore data for the years 2008-2011 and 2012- 
2015 were combined for the analysis. The unadjusted (crude) incidences of serious lifethreatening (including death) medical encounters are available in the online supplementary table S6.

In the adjusted analysis (for age category and sex) incidence of serious life-threatening medical encounter, data were analysed for the two race distances separately and combined. In the INT period, the adjusted incidence (per 1000 runners; 95\% CI) of serious life-threatening (including death) medical encounters was reduced significantly in all runners $(\mathrm{p}=0.0003)$ and $21.1 \mathrm{~km}$ runners $(\mathrm{p}=0.0014)($ table 2$)$.

In $56 \mathrm{~km}$ runners, there was a trend for a reduction in serious life-threatening (including death) medical encounters ( $\mathrm{p}=0.0666)$. In total, in the INT period, there was $64 \%$ reduction in the risk of a serious life-threatening (including death) medical encounter in all runners, with a $74 \%$ and $52 \%$ reduction in the risk for 21.1 and $56 \mathrm{~km}$ runners, respectively.

The NNT statistic of the screening and educational intervention to prevent one serious (lifethreatening/death) medical event was 2670 (for all runners) (unadjusted data).

\section{Race entrants, DNS rate and DNF rate}

The number of race entrants, race starters and finishers, and the percentage (\%) of race entrants that did not start the race or did not finish the race in the CON versus INT period are shown in table 3 . The number of race entrants increased by $31 \%$ from the CON to the INT period. DNS and DNF rates weresimilar in the pre-INT and post-INT periods.

\section{Environmental stress and medical encounter rates}

The environmental conditions on race day for each year and in the CON and INT periods are shown in table 4 .

The means of the calculated WBGT index over the 8-year period ranged from a minimum of 12.1 to 18.4. There was no significant difference in the WBGT index between the CON and the INT period $(\mathrm{p}=0.5289)$. The average wind direction (degrees) was not significantly different in the INT period versus CON period $(\mathrm{p}=0.1431)$. However, the average wind speed (knots) was significantly higher in the INT period versus CON period $(\mathrm{p}<0.0001)$. There was no correlation between either WBGT index $(\mathrm{p}=0.4927)$ or wind speed $\left(\mathrm{p}=0.755^{8}\right)$ and the incidence of all medical encounters over the 8-year study period (online supplementary figure $\mathrm{S} 1$ ).

Finally, the effect of environmental stress on the association between medical encounters and the intervention was also assessed by including wind speed and WBGT index as a confounder in the final model on IRs of all medical encounters. This adjustment of the intervention effect for environmental stress resulted in no significant change to the RR (0.75; 95\% CI 0.62 to 0.91 ) for all medical encounters. 


\section{Race starter risk profile in the InT period}

The observed number and \% race starters in the INT period (consenting race starters; $n=76654$ ) in each risk category (determined by chronic illness and risk factors for chronic illness), by year and race distance in the post-INT period, are depicted in table 5 .

The percentage of 'very high-risk' and 'high-risk' race starters in the 4-year INT period was $3.1 \%$ and $11.0 \%$, respectively, and these were similar in the 21.1 and $56 \mathrm{~km}$ runners (table 5). There was a significant decrease in the combined percentage of 'very high-risk' and 'high-risk' race starters in overthe 4-year period $(2012=16.8 \% ; \quad 2013=14.0 \% ; \quad 2014=13.4 \% ; \quad 2015=12.8 \%)(p<0.0001)$ (adjusted for age category, sex and race distance).

\section{Discussion}

It is well established that the risk of a medical encounter (including sudden death) during prolonged moderate to high-intensity exercise is related to extrinsic factors (environmental stress, 40-42 race distance ${ }^{23}$ ) and intrinsic factors (older age, 81343 men 8 13). Underlying chronic disease and risk factors for chronic disease are recognised as risk factors associated with medical complications during moderate to high-intensity exercise. Therefore, international medical associations have produced consensus-based recommendations/guidelines to screen individuals prior to engaging in moderate to high-intensity exercise. ${ }^{29} 35^{-37} 39$ To our knowledge, this is the first study investigating the efficacy of a prerace medical screening and educational intervention programme to reduce the incidence of all medical encounters in recreational distance runners participating in a mass community-based sports event. In only one other recent study, a prerace educational intervention programme was implemented to reduce the risk of exercise-associated collapse in runners. 44 Our main finding is that a prerace screening and educational intervention was associated with a significant reduction in medical encounters (by 29\%), particularly serious lifethreatening medical encounters (by 64\%). We also show that our observed reductions in medical encounter rates could not be accounted for by known risk factors for medical encounters such as age, sex, race distance and environmental conditions. We also present some data that our intervention programme did not negatively affect overall number of race entrants.

In 2008, we initiated studies to reduce the risk of an adverse medical event during exercise: the SAFER (Strategies to Reduce Adverse Medical Events for the Exerciser) studies. 23 45-47 In the first of these studies, we recorded a high incidence of sudden cardiac death and other serious life-threatening medical complications in runners over a 4-year period (2008-2011). ${ }^{23}$ 


\begin{tabular}{|c|c|c|c|}
\hline & All runners & CON period & INT period \\
\hline Entrants & 188088 & 81345 & 106743 \\
\hline Starters & 153208 & 65865 & 87343 \\
\hline DNS (\%) & 18.5 & 19.0 & 18.2 \\
\hline Finishers & 150177 & 64420 & 85757 \\
\hline DNF (\%) & 2.0 & 2.2 & 1.8 \\
\hline
\end{tabular}

CON, control; INT, intervention.

\begin{tabular}{|c|c|c|c|c|c|c|c|c|c|c|c|}
\hline & \multicolumn{5}{|l|}{ CON period } & \multicolumn{5}{|l|}{ INT period } & \multirow[b]{2}{*}{ P values* } \\
\hline & 2008 & 2009 & 2010 & 2011 & All CON & 2012 & 2013 & 2014 & 2015 & All INT & \\
\hline $\begin{array}{l}\text { Wind direction } \\
\left({ }^{\circ}\right)\end{array}$ & $\begin{array}{l}144 \\
(98-191)\end{array}$ & $\begin{array}{l}148 \\
(101-194)\end{array}$ & $\begin{array}{l}153 \\
(106-200)\end{array}$ & $\begin{array}{l}116 \\
(70-163)\end{array}$ & $\begin{array}{l}140 \\
(116-165)\end{array}$ & $\begin{array}{l}231 \\
(184-277)\end{array}$ & $\begin{array}{l}141 \\
(94-187)\end{array}$ & $\begin{array}{l}143 \\
(96-189)\end{array}$ & $\begin{array}{l}149 \\
(102-195)\end{array}$ & $\begin{array}{l}166 \\
(141-191)\end{array}$ & 0.1431 \\
\hline $\begin{array}{l}\text { Wind speed } \\
\text { (knots) }\end{array}$ & $\begin{array}{l}9.6 \\
(8.2-10.9)\end{array}$ & $\begin{array}{l}7.8 \\
(6.4-9.1)\end{array}$ & $\begin{array}{l}3.5 \\
(2.1-4.8)\end{array}$ & $\begin{array}{l}1.5 \\
(0.1-2.9)\end{array}$ & $\begin{array}{l}5.6 \\
(4.9-6.2)\end{array}$ & $\begin{array}{l}6.9 \\
(5.5-8.3)\end{array}$ & $\begin{array}{l}13.1 \\
(11.7-14.5)\end{array}$ & $\begin{array}{l}9.6 \\
(8.2-10.9)\end{array}$ & $\begin{array}{l}6.6 \\
(5.3-8.0)\end{array}$ & $\begin{array}{l}9.0 \\
(8.4-9.7)\end{array}$ & $<0.0001$ \\
\hline WBGT indext & $\begin{array}{l}16.5 \\
(15.1-17.8)\end{array}$ & $\begin{array}{l}15.4 \\
(14.0-16.8)\end{array}$ & $\begin{array}{l}15.2 \\
(13.8-16.5)\end{array}$ & $\begin{array}{l}13.5 \\
(12.1-14.9)\end{array}$ & $\begin{array}{l}15.1 \\
(14.1-16.2)\end{array}$ & $\begin{array}{l}12.1 \\
(10.7-13.5)\end{array}$ & $\begin{array}{l}18.4 \\
(17.0-19.7)\end{array}$ & $\begin{array}{l}15.1 \\
(13.7-16.5)\end{array}$ & $\begin{array}{l}13.4 \\
(13.7-14.8)\end{array}$ & $\begin{array}{l}14.7 \\
(13.7-15.8)\end{array}$ & 0.5289 \\
\hline
\end{tabular}

We concluded that it should be a priority to reduce these medical encounters. Therefore, from 2012, we introduced prerace medical screening, as proposed by the EACPR, ${ }^{29}$ with an educational intervention programme at running events. As far as we are aware, this observational study, with a 4-year CON and a 4-year INT period, is the first to show promising results that a prerace medical screening and educational intervention can reduce acute medical encounters in master and leisure athletes who participatein mass community-based distance runningevents.

In this study, we carefully considered other risk factors that may account for variations in medical encounter rates, including age, sex, race distance and environmental stress. We adjusted all IRs for age and sex, and report data separately for the two race distances (21.1 and $56 \mathrm{~km}$ ). We show that the incidence of medical encounters was highest in the longer $56 \mathrm{~km}$ race, and this is consistent with previous findings. ${ }^{23}$ However, we also show that the incidence of medical encounters in the INT period was significantly reduced in both races, particularly serious lifethreatening medical encounters.

We are aware that environmental stress (specifically the WBGT) has been associated with increased risk of medical encounters at endurance sports events, 4041 and there are international guidelines for modification or cancellation of sports events, based on the WBGT. 42 Therefore, we carefully 
considered whether environmental stress (specifically the WBGT index) could account for our observed reduction in medical encounters in the INT period. Our results show that the WBGT over the 8-year period was not related to the incidence of medical encounters, and we attribute this observation to two main factors: the relatively small variation in the WBGT index over the 8-year study period, and that WBGT values were consistently in the 'low to moderate' risk for the entire 8year period. ${ }^{40}$ We note that the highest WBGT value was recorded in the INT period (2013). Our data therefore show that environmental conditions did not account for our observed reduction in medical encounters following the intervention.

We also recognised that the feasibility of implementing preparticipation medical screening is a key aspect for potential wider application. It should be simple, pragmatic, not introduce barriers to participation and not be counterproductive to the public health message of the benefits of regular exercise. A potential threat, largely expressed by race organisers, is that a prerace screening programme would negatively affect race entry numbers and/or result in fewer entrants starting the race. Other concerns could be that runners would have a negative attitude towards the prerace screening process, and that the cost to a healthcare system would increase significantly.

Our results show that the number of race entrants was not reduced in the post-INT period; rather, there was a $31 \%$ growth in race entrants. The percentage of overall entrants not starting the race was similar in the CON and INT periods. Most runners (>70\%) gave consent that their prerace medical data could be used for research, and the \% consenting runners increased over the 4-year period from $62 \%$ in 2012 to $78.4 \%$ in 2015, perhaps indicating that runners did not view the screening and education negatively. We believe the data indicate that prerace medical screening and education did not negatively impact race participation, and the majority of the runners support research endeavours to improve race safety.

We did not specifically study the potential cost implication of runners who were advised to undergo medical clearance before participation. However, only about $14 \%$ of race entrants were in the two higher risk categories, and we advised them to seek medical clearance. Most of these runners are under the care of medical practitioners, and undergo routine medical assessments for these conditions. 


\begin{tabular}{|c|c|c|c|c|c|c|}
\hline Race distance & Risk category & 2012 & 2013 & 2014 & 2015 & All INT \\
\hline \multirow[t]{4}{*}{$21.1 \mathrm{~km}$} & Very high & $364(3.4)$ & $344(3.1)$ & $363(2.9)$ & $356(2.8)$ & $1427(3.0)$ \\
\hline & High & $1480(13.7)$ & 1199 (10.6) & 1319 (10.6) & $1330(10.6)$ & $5328(11.3)$ \\
\hline & Intermediate & $4877(45.2)$ & $4290(38.0)$ & 4865 (39.2) & $4870(38.7)$ & $18902(40.2)$ \\
\hline & Low & 4065 (37.7) & $5453(48.3)$ & $5876(47.3)$ & $6018(47.9)$ & $21412(45.5)$ \\
\hline \multirow[t]{4}{*}{$56 \mathrm{~km}$} & Very high & $174(3.5)$ & $272(3.4)$ & $231(3.0)$ & $257(2.9)$ & $934(3.2)$ \\
\hline & High & $639(12.8)$ & $862(10.9)$ & $802(10.2)$ & $798(9.0)$ & $3101(10.5)$ \\
\hline & Intermediate & $2861(57.3)$ & $4171(52.9)$ & 4207 (53.5) & $4541(51.4)$ & $15780(53.3)$ \\
\hline & Low & $1318(26.4)$ & $2587(32.8)$ & $2620(33.3)$ & $3245(36.7)$ & $9770(33.0)$ \\
\hline \multirow[t]{4}{*}{ All runners } & Very high & $538(3.4)$ & $616(3.2)$ & $594(2.9)$ & $613(2.9)$ & $2361(3.1)$ \\
\hline & High & 2119 (13.4) & $2061(10.8)$ & $2121(10.5)$ & $2128(9.9)$ & $8429(11.0)$ \\
\hline & Intermediate & 7738 (49.1) & $8461(44.1)$ & $9072(44.7)$ & $9411(44.0)$ & $34682(45.2)$ \\
\hline & Low & $5383(34.1)$ & 8040 (41.9) & 8496 (41.9) & $9263(43.2)$ & $31182(40.7)$ \\
\hline
\end{tabular}

Our educational intervention encouraged these runners to discuss the medical considerations when participating in endurance running events with their physician. We suggest that, for these runners, this should not add a cost burden to the healthcare system. The exception would be a small number of runners who reported only symptoms suggestive of CVD. This would result in a new consultation with a medical practitioner, and be an additional cost to the healthcare system. However, this has to be balanced with the cost saving associated with any reduction in medical encounters during exercise.

We do not have any data on the risk profile (chronic illness and risk factors for chronic illness) of race entrants in the 4-year CON period. These data have never been reported, and we could not obtain these data without informing race entrants of increased risk of a medical complication during exercise, as this would have important ethical implications. However, we could study the effects of the intervention programme on altering the risk profile of race starters, but only in the 4-year INT period. We were encouraged by the observation that there was a significant reduction in the \% 'very high-risk' or 'high-risk' race starters over the 4-year intervention, and we note that the largest reduction was after the first year in the INT period.

The strengths of this study are the large number of runners studied over an 8-year period, the accurate and consistent documentation of the medical encounters, that we adjusted medical encounter rates for risk factors such as age, sex and race distance, and that we show that environmental stress, specifically WBGT index, did not account for our observed reduction in medical encounters. This study has several limitations. First, this was not a randomised controlled trial, but rather a pragmatic field study, and we therefore cannot conclude that the reduction in the incidence of medical encounters was only as a result of our intervention. Second, we acknowledge that the intervention consisted of multiple components including screening and risk stratification, combined with an individually targeted educational intervention for 'very high-risk' and 'high-risk' subgroups and a general educational intervention for all runners. Therefore, any effect of our intervention cannot be attributed to a single component of the intervention. Third, we relied on self-reported data from runners. Fourth, we acknowledge that we do not have data on the individual runner risk profile (chronic illness and risk factors) in the CON period and therefore we cannot show that the risk 'profile' of runners differed in the CON and INT periods. Finally, we also do not 
report any data to show that runners complied with the advice to seek medical clearance, but we did collect information on how many runners sought medical clearance in the period 2013-2015. Larger studies, including more endurance events and thus more serious medical encounters, are needed to confirm the results of the present study.

In summary, our study shows promising results that following the introduction of an online prerace medical screening and educational intervention programme at a mass communitybased running event, we observed a reduction in all medical encounters, mainly in longer races, and serious life-threatening medical encounters, mainly in the shorter race. In addition, the screening and intervention programme was easily accomplished, and appears to alter the race starter risk profile. Therefore, a prerace screening and educational intervention has the potential to change current practice worldwide and we suggest that race organisers and race medical teams may consider implementing such programmes to improve race safety. 


\section{References}

1. Pedersen BK, Saltin B. Exercise as medicine - evidence for prescribing exercise as therapy in 26 different chronic diseases. Scand J Med Sci Sports 2015;25 Suppl 3:1-72.

2. Haskell WL, Lee IM, Pate RR, et al. Physical activity and public health: updated recommendation for adults from the American College of Sports Medicine and the American Heart Association. Circulation 2007;116:1081-93.

3. Khan KM, Thompson AM, Blair SN, et al. Sport and exercise as contributors to the health of nations. Lancet 2012;380:59-64.

4. Kohl HW, Craig CL, Lambert EV, et alThe pandemic of physical inactivity: global action for public health. Lancet 2012;380:294-305.

5. Warburton DE, Bredin SS. Reflections on physical activity and health: what should we recommend? Can J Cardiol 2016;32:495-504.

6. WHO. Global Recommendations on Physical Activity for Health. Geneva: World Health Organization (WHO), 2010.

7. Vanhees L, De Sutter J, GeladaS N, et al. Importance of characteristics and modalities of physical activity and exercise in defining the benefits to cardiovascular health within the general population: recommendations from the EACPR (Part I). Eur J Prev Cardiol 2012;19:670-86.

8. Chugh SS, Weiss JB. Sudden cardiac death in the older athlete. $J$ Am Coll Cardiol 2015;65:493-502.

9. Sanchez LD, Corwell B, Berkoff D. Medical problems of marathon runners. Am J Emerg Med 2006;24:608-15.

10. Schwellnus MP. Premarathon evaluations: is there a role for runner prerace medical screening and education to reduce the risk of medical complications? Curr Sports Med Rep 2017:16:12936.

11. Thompson PD, Franklin BA, Balady GJ, et al. Exercise and acute cardiovascular events placing the risks into perspective: a scientific statement from the American heart association council on nutrition, physical activity, and metabolism and the council on clinical cardiology. Circulation 2007;115:2358-68.

12. Eijsvogels TM, Molossi S, Lee DC, et al. Exercise at the extremes: the amount of exercise to reduce cardiovascular events. J Am Coll Cardiol 2016;67:316-29.

13. Goodman JM, Burr JF, Banks L, et al. The acute risks of exercise in apparently healthy adults and relevance for prevention of cardiovascular events. Can J Cardiol 2016;32:523-32.

14. Mont L, Pelliccia A, Sharma S, et al. Pre-participation cardiovascular evaluation for athletic participants to prevent sudden death: Position paper from the EHRA and the EACPR, ranches of the ESC. Endorsed by APHRS, HRS, and SOLAECE. Eur J Prev Cardiol 2017;24:41-69.

15. Day SM, Thompson PD. Cardiac risks associated with marathon running. Sports Health 2010;2:301-6.

16. Siegel AJ. Pheidippides redux: reducing risk for acute cardiac events during marathon running. Am J Med 2012;125:630-5.

17. Maron BJ, Poliac LC, Roberts WO. Risk for sudden cardiac death associated with marathon running. JAm Coll Cardiol 1996;28:428-31.

18. Roberts WO, Maron BJ. Evidence for decreasing occurrence of sudden cardiac death associated with the marathon. J Am Coll Cardiol 2005;46:1373-4. 
19. Webner D, DuPrey KM, Drezner JA, et al. Sudden cardiac arrest and death in United States marathons. Med Sci Sports Exerc 2012;44:1843-5.

20.Tunstall Pedoe DS. Marathon cardiac deaths : the london experience. Sports Med 2007;37(45):448-50.

21. Kim JH, Malhotra R, Chiampas G, et al. Cardiac arrest during long-distance running races. $N$ Engl J Med 2012;366:130-40.

22. Yankelson L, Sadeh B, Gershovitz L, et al. Life-threatening events during endurance sports: is heat stroke more prevalent than arrhythmic death? J Am Coll Cardiol 2014;64:463-9.

23. Schwabe K, Schwellnus M, Derman W, et al. Medical complications and deaths in 21 and $56 \mathrm{~km}$ road race runners: a 4-year prospective study in 65865 runners-SAFER study I. Br J Sports Med 2014;48:912-8.

24. Nguyen RB, Milsten AM, Cushman JT. Injury patterns and levels of care at a marathon. Prehosp Disaster Med 2008:23:519-25.

25. Crouse BJ. Marathon day. A view from the medical tent. Minn Med 1996;79:10-11.

26. Kretsch A, Grogan R, Duras P, et al. 1980 Melbourne marathon study. Med J Aust 1984;141:809-14.

27. Roberts WO. A 12-yr profile of medical injury and illness for the twin cities marathon. Med Sci Sports Exerc 2000;32:1549-55.

28. Turris SA, Lund A, Mui J, et al. An organized medical response for the Vancouver International Marathon (2006-2011): when the rubber hits the road. Curr Sports Med Rep 2014:13:147-54.

29. Borjesson M, Urhausen A, Kouidi E, et al. Cardiovascular evaluation of middle-aged/ senior individuals engaged in leisure-time sport activities: position stand from the sections of exercise physiology and sports cardiology of the European Association of Cardiovascular Prevention and Rehabilitation. Eur J Cardiovasc Prev Rehabil 2011;18:446-58.

30. Corrado D, Pelliccia A, Bjørnstad HH, et al. Cardiovascular pre-participation screening of young competitive athletes for prevention of sudden death: proposal for a common european protocol. consensus statement of the study group of sport cardiology of the working group of cardiac rehabilitation and exercise physiology and the working group of myocardial and pericardial diseases of the european society of cardiology. Eur Heart $J$ 2005;26:516-24.

31. Maron BJ, Thompson PD, Ackerman MJ, et al. Recommendations and considerations related to preparticipation screening for cardiovascular abnormalities in competitive athletes: 2007 update: a scientifi statement from the American Heart Association Council on Nutrition, Physical Activity, and Metabolism: endorsed by the American College of Cardiology Foundation. Circulation 2007;115:1643-455.

32. Thünenkötter T, Schmied C, Dvorak J, et al. Benefits and limitations of cardiovascular precompetition screening in international football. Clin Res Cardiol 2010;99:29-35.

33. Ljungqvist A, Jenoure P, Engebretsen L, et al. The International Olympic Committee (IOC) Consensus Statement on periodic health evaluation of elite athletes March 2009. Br J Sports Med 2009;43:631-43.

34. Aagaard P, Sahlén A, Bergfeldt L, et al. Preparticipation evaluation of novice, middle- age, longdistance runners. Med Sci Sports Exerc 2013;45:130-7. 
35. Bredin SS, Gledhill N, Jamnik VK, et al. PAR-Q+ and ePARmed-X+: new risk stratification and physical activity clearance strategy for physicians and patients alike. Can Fam Physician 2013;59:273-7.

36. Maron BJ, Araújo CG, Thompson PD, et al. Recommendations for preparticipation screening and the assessment of cardiovascular disease in masters athletes: an advisory for healthcare professionals from the working groups of the world heart federation, the international federation of sports medicine, and the american heart association committee on exercise, cardiac rehabilitation, and prevention. Circulation 2001;103:327-34.

37. Riebe D, Franklin BA, Thompson PD, et al. Updating ACSM's recommendations for exercise preparticipation health screening. Med Sci Sports Exerc 2015;47:2473-9.

38. Schwabe K, Schwellnus M, Swanevelder S, et al. Leisure athletes at risk of medical complications: outcomes of pre-participation screening among 15,778 endurance runners SAFER VII. Phys Sportsmed 2018:1-9.

39. Corrado D, Schmied C, Basso C, et al. Risk of sports: do we need a pre-participation screening for competitive and leisure athletes? Eur Heart $J$ 2011;32:934-44.

40. Roberts WO. Heat and cold: what does the environment do to marathon injury? Sports Med 2007;37(4-5):400-3.

41. Roberts WO. Determining a "do not start" temperature for a marathon on the basis of adverse outcomes. Med Sci Sports Exerc 2010;42:226-32.

42. Armstrong LE, Casa DJ, Millard-Stafford M, et al. American College of Sports Medicine position stand. Exertional heat illness during training and competition. Med Sci Sports Exerc 2007;39:556-72.

43. Sanchis-Gomar F, Santos-Lozano A, Garatachea N, et al. My patient wants to perform strenuous endurance exercise. What's the right advice? Int J Cardiol 2015;197:248-53.

44. Worley DM, Renier CM, Woehrle TA, et al. Preventing exercise-associated collapse using online runner education: a randomized, controlled trial. Clin J Sport Med 2018.

45. Schwabe K, Schwellnus MP, Derman W, et al. Older females are at higher risk for medical complications during $21 \mathrm{~km}$ road race running: a prospective study in 39511 race startersSAFER study III. Br J Sports Med 2014;48:891-7.

46. Schwellnus M, Derman W. The quest to reduce the risk of adverse medical events in exercising individuals: introducing the SAFER (Strategies to reduce Adverse medical events For the ExerciseR) studies. Br J Sports Med 2014;48:869-70.

47. Schwabe K, Schwellnus MP, Derman W, et al. Less experience and running pace are potential risk factors for medical complications during a $56 \mathrm{~km}$ road running race: a prospective study in 26354 race starters-SAFER study II. Br J Sports Med 2014;48:905-11. 